\title{
Um futuro alternativo para São Paulo: Anhaia Mello e a tese da limitação do crescimento da metrópole ${ }^{1}$
}

An alternative future to São Paulo: Anhaia Mello and the thesis of metropolis growth limitation

Bruno de Macedo Zorek ${ }^{*}$

\begin{abstract}
Resumo
O objetivo deste artigo é apresentar um ponto de vista alternativo sobre o futuro de São Paulo que, em função de uma série de transformações enfrentadas pela metrópole na década de 1950, acabou servindo como ponte para a inversão dos valores hegemônicos em relação ao crescimento da cidade. Esse ponto de vista alternativo foi encarnado fundamentalmente pelo urbanista Luís de Anhaia Mello, que desenhava uma São Paulo polinucleada, com cinturões verdes em torno de cada núcleo populacional e com sua população, sua indústria, seus serviços redistribuídos de forma descentralizada por um amplo território. Como guia condutor da análise, o artigo segue um documento específico, produzido em 1954 por Anhaia Mello, em que ele descreve, de maneira clara, o que imaginava dever ser o futuro da cidade. Através desse documento, procura-se acompanhar a transformação simbólica que fez a metrópole de 400 anos deixar de ser uma promessa de sucesso e passar a ser encarada como uma cidade condenada ao caos.
\end{abstract}

Palavras-chave: Anhaia Mello; São Paulo; Representações de futuro; Representações de cidade.

\begin{abstract}
The aim of this paper is to present an alternative point of view on the future of São Paulo that, due to a series of transformations faced by the city in the $1950 \mathrm{~s}$, ended up serving as a bridge to the reversal of hegemonic values in relation to the city's growth. This alternative point of view was mainly embodied by the urban planner Luís Anhaia Mello, who drew one polynuclear São Paulo, with green belts around each population center and its population, its industry, its services redistributed in a decentralized manner by a large territory. As the driver guide of the analysis, this paper follows a specific document produced in 1954 by Anhaia Mello, where he describes clearly what he imagined should be the future of the city. Through this document, we try to follow the symbolic transformation that made the 400 years metropolis ceased to be a promise of success and become seen as a city doomed to chaos.
\end{abstract}

Keywords: Anhaia Mello; São Paulo; Representations of future; Representations of city.

Este artigo discute as representações de futuro da cidade de São Paulo, elaboradas na década de 1950, por Luís de Anhaia Mello - um importante e influente urbanista na época. O objetivo central é mostrar como as ideias desse urbanista organizaram a inversão dos valores com que se olhava para o crescimento da metrópole. Antes de suas ideias ganharem visibilidade, o futuro de São Paulo era hegemonicamente

\footnotetext{
${ }^{1}$ Pesquisa financiada pela Fundação de Amparo à Pesquisa do Estado de São Paulo (FAPESP).

* Doutorando em História pela Universidade Estadual de Campinas (UNICAMP).
}

Recebido em outubro de 2016 | Aprovado em fevereiro de 2017. 
representado como o de um contínuo crescimento - e isso era bom. Embora Anhaia Mello defendesse que São Paulo deveria parar de crescer, a perspectiva de que a cidade continuaria se expandindo não se alterou. O que mudou, no entanto, foi que esse crescimento passou a ser visto como algo ruim. O papel desempenhado por Anhaia Mello nas transformações das representações do futuro da metrópole teve um efeito duplo: em primeiro lugar, ajudou a demolir a perspectiva otimista sobre o crescimento de São Paulo, uma perspectiva cuja produção era trabalho, sobretudo de urbanistas; e, em segundo lugar, ajudou a transferir a prerrogativa da produção hegemônica da representação da cidade das mãos dos urbanistas para as dos cientistas sociais, geógrafos e outros profissionais das humanidades. Essa passagem sedimentou o pessimismo que passou a dominar as representações do futuro de São Paulo, do final dos anos 1950 em diante. O foco desse artigo é a análise das ideias que construíram aquela passagem.

Em 1954, quando completou 400 anos, São Paulo era descrita como a cidade que mais crescia no mundo. Era tida como o maior centro industrial da América Latina, dizia-se que a cada 20 minutos uma casa era levantada em seu tecido urbano - e esse discurso vinha acompanhado de outras avaliações positivas sobre sua grandiosidade, como matéria publicada no O Estado de São Paulo, em 25 de janeiro de 1954 (FERNANDES, 2008; ARRUDA; 2001). Foi mais ou menos nesse momento que a metrópole ultrapassou a marca de três milhões de habitantes, superando a população do Rio de Janeiro e, portanto, tornando-se a maior cidade brasileira (AZEVEDO, 1958; SANTOS, 2009). Ainda no ano do quarto centenário, Florestan Fernandes - que no momento começava a se destacar como um sociólogo de relevância nacional e estabelecia as bases do grupo que mais tarde ficou conhecido como "Escola Sociológica Paulista”, conforme Garcia, (2002):

[São Paulo] tornou-se uma cidade grande, dotada de uma complicada rede de comunicações e de transportes, de uma extensa área urbana, consideravelmente diferenciada, de um sistema comercial, industrial e bancário altamente complexo e com tendências expansivas, de meios modernos de educação, de assistência e de recreação. Centro de grandes operações financeiras, para ela convergem os capitais do Estado de São Paulo e dela dependem as mais importantes [iniciativas] de desenvolvimento econômico das regiões rurais de várias zonas do país, principalmente nos Estados do Paraná, Mato Grosso, Goiás e Minas Gerais. Aberta a todas as influências, está em comunicação econômica e cultural contínua com a maioria dos países europeus e americanos, sendo ela própria uma das aglomerações mais cosmopolitas do Brasil e da América Latina. (FERNANDES, 2008, p. 187 - grifos no original). 
$\mathrm{Na}$ sequência, e esse ponto merece ser frisado, Fernandes (2008, p. 187) complementava: "os paulistas se envaidecem com tudo isso", chamando a atenção para a tendência geral de representação da cidade naquele momento, segundo a qual, quanto maior fosse São Paulo, melhor ela seria.

Também no mesmo contexto, mas na contramão dessa perspectiva, Luís Ignácio de Anhaia Mello - um urbanista veterano e referência importante nos debates sobre São Paulo - via com preocupação o crescimento da metrópole. Se continuasse no mesmo passo, conforme o urbanista, São Paulo caminharia para um "verdadeiro suicídio coletivo" (ANHAIA MELLO, 1950, p. 27). Caso nada fosse feito para impedir esse destino, São Paulo se transformaria em uma "necrópolis", uma cidade gigantesca dominada por “doenças, fome [e] guerra civil”, pontua (ANHAIA MELLO, 1954, p. 34). Para o urbanista: "o problema das grandes metrópoles [era] diminuir a população, e não aumentá-la" Mello (1954, p. 39), uma observação que não deixava espaço para dúvidas: "a tese da limitação do crescimento é incontestável”, assevera Anhaia Mello (1954, p. 14).

Anhaia Mello havia chegado aos anos 1950 como uma figura bastante respeitada nos debates urbanísticos. Nasceu em 1891, em São Paulo, no seio uma família de industriais, cursou Engenharia e Arquitetura na Escola Politécnica de São Paulo, formando-se em 1913. Alguns anos depois de formado, tornou-se professor da Escola Politécnica e passou a se dedicar ao estudo do urbanismo. Começou a escrever e publicar, na área, na segunda metade da década de 1920 e, a partir de então, foi aos poucos se tornando conhecido como estudioso do tema. Ainda na década de 1920, ocupou o cargo de vereador em São Paulo, por um mandato. Em dezembro de 1930 assumiu a prefeitura da cidade, por indicação do interventor federal João Alberto Lins de Barros. Contudo, quando Barros foi substituído, em julho de 1931, Anhaia Mello também foi afastado da prefeitura. Já durante o Estado Novo, aceitou administrar a Secretaria de Viação e Obras Públicas do Estado de São Paulo, onde trabalhou de 1937 a 1943. Depois disso, voltou a dedicar-se ao ensino universitário e aos estudos de urbanismo, em que já se destacava como uma referência importante. Nesse contexto, é relevante lembrar que, naquele momento, o campo intelectual paulistano, ainda em processo de formação, dependia grandemente das dinâmicas do campo político portanto, era comum ter personagens cuja distinção se dava justamente pelo cruzamento 
de suas posições em ambos os universos ${ }^{2}$ - Anhaia Mello é justamente um exemplo disso. $\mathrm{Na}$ segunda metade dos anos 1940, foi um dos principais articuladores da fundação da Faculdade de Arquitetura e Urbanismo da USP, faculdade da qual foi o primeiro diretor (ABREU, 2001; BRESCIANI; 2010; 2014).

Na inauguração da década de 1950, com então quase 60 anos de idade, Anhaia Mello era professor na FAU-USP, consolidara-se como o principal nome de uma vertente do urbanismo brasileiro, era membro atuante da Sociedade Amigos da Cidade instituição que reunia os principais arquitetos e urbanistas de São Paulo -, além de ser um frequente articulista do Boletim do Instituto de Engenharia e da Revista de Engenharia - dois dos periódicos mais importantes para a área do urbanismo Bresciani (2010; 2014); Leme (2001); Feldman (2005). Anhaia Mello, portanto, encarnava as autoridades de estadista, de acadêmico e de urbanista profissional. Contudo, essas autoridades todas, no caso em questão, tinham uma peculiaridade: o urbanista representava posições "alternativas", sempre deslocadas em relação às tendências dominantes.

A condição de representante de pontos de vista alternativos e que desafiavam as perspectivas hegemônicas era o que fundamentava o lugar-social ocupado por Anhaia Mello. ${ }^{3}$ Sua posição lhe permitia articular três perspectivas "dominadas" sobre a cidade de São Paulo, conferindo-lhes uma força que individualmente não teriam. Como estadista, frequentemente esteve na oposição - não uma oposição extrema, mas sim, uma razoavelmente comportada, de caráter liberal, que questionava a situação, sempre através das regras estabelecidas. Como acadêmico, foi um dos principais promotores de uma importante ruptura na Escola Politécnica da USP, que, a partir da criação da Faculdade de Arquitetura e Urbanismo, em 1948, retirou a Arquitetura da alçada dos engenheiros. Embora essa ruptura tenha garantido um lugar central para Anhaia Mello na nova faculdade, proporcionando-lhe também espaço institucional para se firmar como uma das principais referências do urbanismo brasileiro, ao mesmo tempo, acabou lhe afastando da tradicional e poderosa Escola Politécnica ${ }^{4}$, onde outras vertentes do urbanismo eram cultivadas (LEME, 2001; MEYER, 1991; FICHER, 2005).

\footnotetext{
${ }^{2}$ Sobre o desenvolvimento do campo intelectual em São Paulo, consultar: Miceli (1995; 2001a; 2001b; 2012) e Pontes (1998).

${ }^{3}$ Sobre o conceito de lugar-social, ver Certeau (1982).

${ }^{4}$ A Escola Politécnica, a Faculdade de Direito do Largo de São Francisco e a Escola de Medicina eram as três faculdades tradicionais de São Paulo antes da criação de USP, em 1934. A partir de 1934, as três escolas foram incorporadas à universidade, mas continuaram representando os centros mais prestigiosos da nova instituição (MICELI, 2001a).
} 
Como arquiteto e urbanista, finalmente, Anhaia Mello era fundamentalmente, um teórico, pois praticamente não teve oportunidades de experimentar suas ideias em larga escala. Talvez sua única grande chance nesse sentido tenha sido seu período como prefeito de São Paulo, mas ele administrou a cidade por muito pouco tempo (menos de oito meses) e, em meio a uma crise política aguda, provocada pela revolução de 1930, não contou, portanto, com condições favoráveis para aplicar seus princípios.

Essa condição triplamente "dominante-dominada" ganhou força especial durante uma conjuntura específica. O urbanismo hegemônico em São Paulo, caracterizado pelo estímulo ao crescimento contínuo da metrópole e, preocupado em encontrar soluções pragmáticas para desobstruir e suavizar esse crescimento havia sofrido alguns abalos de ordem política. Durante praticamente todo o Estado Novo, o prefeito de São Paulo foi Francisco Prestes Maia que, assim como Anhaia Mello, era um engenheiro-arquiteto, professor da Escola Politécnica e estudioso do urbanismo.

No entanto, Prestes Maia era o principal representante da perspectiva urbanística oposta à defendida por Anhaia Mello. Ele era o campeão daquele urbanismo pragmático que valorizava o crescimento contínuo da cidade - e durante sua prefeitura, promoveu uma série importante de reformas urbanas alinhadas a essa perspectiva (CARPINTÉRO, 1998; MEYER, 1991).

Com o fim da ditadura de Vargas, o tipo de urbanismo representado por Prestes Maia foi relativamente estigmatizado como antidemocrático, o que lhe fez perder forças nos debates sobre quais seriam as melhores escolhas de futuro para São Paulo, embora isso não significasse a perda da hegemonia, mas simplesmente o estabelecimento de um jogo político mais equilibrado. ${ }^{5}$ Enquanto isso, no mundo intelectual, Anhaia Mello vivia o auge de sua carreira, sendo respeitado como uma referência incontornável nos debates sobre a urbanização de São Paulo e, portanto, uma voz sempre presente e sempre requisitada (FELDMAN, 2005; LEME, 2001; BRESCIANI, 2010, 2014; MEYER, 1991). Finalmente, na prática urbanística da metrópole, ainda que Anhaia Mello não tivesse poder de decisão, suas ideias se tornaram muito influentes, sobretudo no Departamento de Urbanismo do município, criado em 1947 (FELDMAN, 2005) em parte por conta do enfraquecimento da principal perspectiva concorrente.

Esses três elementos, que por si sós já favoreciam o fortalecimento das ideias de Anhaia Mello, foram potencializados em função das comemorações do IV Centenário,

\footnotetext{
${ }^{5}$ Sobre a estigmatização do urbanismo de Prestes Maia como anti-democrático, principalmente as críticas de Anhaia Mello e suas ponderações sobre um urbanismo democrático, ver Anhaia Mello (1950).
} 
quando se multiplicaram enormemente os discursos sobre São Paulo. Esse movimento provocou dois efeitos fundamentais: de um lado, consolidou-se, pela repetição exaustiva, uma representação positiva da grandiosidade e do crescimento de São Paulo; de outro, abriu-se espaço para que autoridades consolidadas se destacassem em meio a esse mar de discursos, especialmente quando se diferenciavam da ladainha laudatória. Sendo assim, o excesso de discursos produzidos em torno do aniversário da cidade foi um dos elementos centrais no processo de potencialização das ideias de Anhaia Mello, trazendo-as para o primeiro plano e produzindo efeitos disruptivos nas representações hegemônicas sobre a metrópole e seu futuro. A partir dessa disrupção e dos desdobramentos dos debates que se seguiram, um conjunto de perspectivas paralelas sobre São Paulo se consolidou, redefinindo e complexificando a produção, no sentido amplo, da cidade, de suas representações e de seu futuro.

Foi em uma palestra realizada no final de 1954 (ano do IV Centenário), mais precisamente em 8 de novembro, dia mundial do urbanismo, que Anhaia Mello apresentou, da maneira mais explícita em sua obra, qual era seu ponto de vista sobre o futuro de São Paulo (ANHAIA MELLO, 1954). Essa palestra será o principal documento, aqui analisado e será encarado, sobretudo como uma peça retórica.

Em sua palestra, Anhaia Mello assumiu uma postura bastante pessimista em relação ao futuro de São Paulo. Em contraste com o clima geral, festivo e otimista, o urbanista desenhava um futuro apocalíptico para a metrópole. Contudo, esse não seria um destino inevitável, uma vez que São Paulo poderia ser salva, desde que fossem tomadas uma série de providências. Como se chamou a atenção acima, as peculiaridades do lugar de fala de Anhaia Mello, que articulava três condições "dominadas" de três cenários diferentes - o político, o acadêmico, e o urbanístico -, lhe permitiam distanciar-se das representações dominantes e, o que é mais importante, questioná-las, invertendo seus valores.

De início, o urbanista traz a seguinte avaliação sobre a situação da população humana em geral:

\footnotetext{
Os urbanistas de todo o mundo são hoje unanimes em afirmar que o sistema de distribuição das populações sôbre o solo, consequência da Revolução Industrial e Demográfica, e característico da época paleotécnica, hoje ainda prevalecente, está errado e é desumano e anti-social. (ANHAIA MELLO, 1954, p. 1 - grifos no original).
}

Há três elementos que importam ser destacados desse trecho. Em primeiro lugar, a suposta unanimidade dos urbanistas em torno da avaliação apresentada. O que estava 
em jogo nessa afirmação era a reivindicação do uso legítimo da autoridade de urbanista. Ao restringir o universo de urbanistas somente àqueles que concordavam com a existência de um erro na distribuição da população sobre o solo, Anhaia Mello excluía deste universo todos os que não viam maiores problemas nessa distribuição. No caso, isso significava negar a autoridade de urbanistas a qualquer um que se identificasse com o modelo hegemônico de urbanismo e, em particular, a figuras como o já mencionado Prestes Maia ou Robert Moses - homem público estadunidense, reconhecido como urbanista, e que foi o principal autor de um "Programa de Melhoramentos Públicos para São Paulo", encomendado pela prefeitura da cidade e entregue em 1950. ${ }^{6}$ Ambos, embora ocupassem posições bastante distintas no universo do urbanismo, representavam para Anhaia Mello o tipo específico de urbanização que ele atacava. Um movimento ousado, proveniente de uma posição desafiante, dado que, pelo menos em São Paulo, os urbanistas que detinham a hegemonia - embora abalada - tanto sobre as representações da metrópole, quanto sobre as políticas urbanas eram justamente aqueles que não viam as condições de distribuição da população sobre o solo como problemáticas.

Em segundo lugar, Anhaia Mello indica ser adepto de uma determinada "filosofia da história", de caráter voluntarista, que mais adiante em sua palestra se tornará mais clara. De qualquer forma, já nesse trecho está claro que, em sua opinião, desde pelo menos a Revolução Industrial, a humanidade estaria trilhando um caminho equivocado. Ao mesmo tempo, estava implícito que, através de determinadas ações racionais e planejadas - e aí está o voluntarismo -, seria possível corrigir esta rota.

Em terceiro lugar, finalmente, e complementando tanto a "filosofia da história" implícita quanto à restrição do universo dos urbanistas, merece destaque a noção de erro apresentada por Anhaia Mello. Para o urbanista, haveria, por oposição lógica, uma maneira correta de se ordenar as cidades, que seguiria princípios apresentados adiante em sua palestra, e uma série de maneiras incorretas, cuja aplicação levaria ao apocalipse urbano. Nesse sentido, o que teria predominado na urbanização de São Paulo (e na de outras cidades) até então, seria o erro, pois a metrópole estaria se encaminhando para o caos. Disso decorria também que os responsáveis por essa urbanização não pudessem ser considerados urbanistas, dado que estavam errados em suas políticas para a cidade, ao passo que os urbanistas legítimos seriam conscientes de que o caminho até então

\footnotetext{
${ }^{6}$ Sobre Robert Moses, consultar Caro (1975); Ballon e Jackson (20070. Sobre seu plano urbanístico para São Paulo, ver Leme (2011); Campos (2002); Siwi (s/d); Feldman (2005).
} 
seguido, não era o correto. O par oposto certo e errado, por fim, sugere, senão um modelo único, ao menos uma variedade limitada de modelos corretos de urbanização, condenando a maior parte dos modelos de cidades, reais ou imaginadas, ao limbo mais ou menos indefinido da urbanização equivocada.

É interessante contrastar essa redução do universo de urbanistas, feita por Anhaia Mello em 1954, com a concepção que o mesmo apresentara um quarto de século antes. No final da década de 1920, quando ele, um jovem professor da Escola Politécnica, começava a divulgar uma prática profissional ainda incipiente no Brasil, o urbanismo era então descrito de forma muito mais inclusiva:

\begin{abstract}
Diz o rifão popular que o segredo é a alma do negocio. O segredo, creio, eu, afasta a concurrencia. Neste grande negocio do urbanismo, porem, da-se justamente o contrario: a publicidade ampla é a sua alma. Porque ninguem tem mais direito de conhecer antecipadamente os detalhes do negocio, de que o socio capitalista que é o publico. [...] Mas para transformar em realidade os beneficios que a technica da engenharia pode trazer para a vida em commum é necessaria e imprescindivel a collaboração e cooperação do jurista, do legislador, do economista, do sociologo, dos governos que dão força ás iniciativas e adoptam dispositivos convenientes á sua efficacia, do cidadão que se submette de bom grado ao sacrificio de algumas das proprias commodidades e proveitos pelo bem geral. (ANHAIA MELLO, 1928, p. 235; 238).
\end{abstract}

Portanto, esse urbanismo cooperativo do final da década de 1920 foi substituído, em meados da de 1950, por um segundo urbanismo, marcado pela exclusividade e controlado por uma espécie de "clube de especialistas" (com conhecimentos técnicos indisputáveis e que pensavam de forma unânime). O primeiro urbanismo foi formulado por Anhaia Mello quando era importante para ele garantir para si um lugar ao sol nos debates e políticas sobre São Paulo, e tecer redes que o ajudassem a capitalizar sua condição. Enquanto a segunda concepção foi elaborada quando a posição de Anhaia Mello era a de um urbanista, acadêmico e estadista de autoridade reconhecida.

Não é apenas a transformação do lugar-social de Anhaia Mello, ao longo de sua trajetória, que explica sua mudança de postura. A cidade de São Paulo triplicara de tamanho nos vinte e cinco anos que separam uma manifestação da outra. Foi mais ou menos em 1930, que São Paulo alcançou seu primeiro milhão de habitantes. Em meados da década de 1950, por sua vez, a metrópole atingiu a marca de três milhões. ${ }^{7}$ Portanto, duas São Paulo que ofereciam dois contextos urbanos completamente diferentes.

\footnotetext{
${ }^{7}$ Sobre o comportamento demográfico de São Paulo, ver Santos (2009).
} 
Além disso, os debates próprios do urbanismo paulistano se adensaram enormemente no mesmo período. A produção teórica foi liderada por Prestes Maia, pelo próprio Anhaia Mello e por outros engenheiros e arquitetos que passaram a se interessar pelo urbanismo. Desenhou-se, nesse sentido, uma oposição equivalente àquela que Françoise Choay identifica no urbanismo europeu e estadunidense: de um lado, um modelo progressista, e, de outro, um culturalista (CHOAY, 2010). Como chama a atenção a arquiteta e historiadora da arquitetura, Sarah Feldman, embora a classificação de Choay seja esquemática, datada e ultrapassada, suas categorias funcionam para explicar as principais diferenças entre Anhaia Mello e Prestes Maia (FELDMAN, 2005). Em poucas palavras, o modelo progressista, associado a Prestes Maia, pode ser caracterizado por uma aposta no crescimento contínuo das cidades, nos valores da velocidade e da concentração (humana, de serviços, de capitais, etc.); enquanto o modelo culturalista, vinculado a Anhaia Mello, abominava a grande metrópole, tendo pequenas comunidades, de inspiração pré-industrial, como sua referência do que deveria ser uma cidade saudável (CHOAY, 2010; FELDMAN, 2005).

No caso de São Paulo, o primeiro modelo era o hegemônico, enquanto o segundo se ocupava de propor soluções alternativas para a cidade e a fazer a crítica do modelo dominante, conforme Leme (2001); Ficher (2005); Feldman (2005); Meyer (1991). Essa divisão teórica entre os urbanistas quase coincidia com suas posições políticas. Aqueles que se identificavam ao modelo progressista geralmente estavam associados a uma elite conservadora e tradicional - como é o caso de Prestes Maia. Ao passo que os identificados ao modelo culturalista tendiam a se associar aos grupos politicamente mais liberais (e geralmente de oposição) e a uma elite moderna - como o próprio Anhaia Mello. Em termos de políticas urbanísticas ensaiadas ou efetivamente implantadas, merecem destaque: em primeiro lugar, a prefeitura de Fábio Prado (19341938), da qual Anhaia Mello participou informalmente como conselheiro, e que realizou intervenções na cidade inspiradas em ambos os modelos de urbanismo disponíveis; em segundo lugar, a prefeitura de Prestes Maia (1938-1945), em que São Paulo passou por uma importante reforma urbana, nesse caso, completamente forjada a partir do modelo progressista e que definiu os rumos do desenvolvimento posterior da cidade; e, em terceiro lugar, a administração de Lineu Prestes (1950-1951), em que um novo plano de 
urbanização foi elaborado, também nos moldes do modelo progressista, embora sua implantação tenha sido apenas parcial e objeto de críticas importantes. ${ }^{8}$

As transformações em São Paulo, o adensamento das discussões sobre cidades, e a realização de uma série de intervenções na metrópole que punham à prova as teorias urbanísticas disponíveis, além da posição de liderança de "oposição" que Anhaia Mello ocupava nos debates do urbanismo, são os principais eixos que explicam a adoção de uma postura mais combativa por parte deste urbanista nos anos 1950, revelada no ataque aos erros que levavam a um ordenamento "desumano e anti-social" de São Paulo.

Na palestra, Anhaia Mello passa daquela observação geral sobre a distribuição da população humana sobre o solo para uma escala mais reduzida, considerando então, o caso brasileiro. Conforme sua análise, a população brasileira estaria distribuída de maneira completamente irregular pelo território nacional. Haveria "imensas áreas abandonadas", como as regiões Norte e Centro-Oeste do país. As regiões rurais constituiriam um território de tipo hostil, onde "o homem [estaria] disperso e abandonado, perdido nas distâncias imensas, sem um mínimo de equipamento social capaz de integrá-lo na cultura". Nos povoados e vilas, que estariam "congelados material e socialmente", não haveria infraestrutura suficiente. Nas palavras do urbanista, nessas localidades "não [havia] transportes nem comunicações; nem assistência nem higiene, nem orientação educacional; fomento e assistência técnica, mecanização ou crédito". Eram lugares "crescendo ou estagnando ao léo [...], na poeira ou na lama dos cruzamentos de estradas ou simples caminhos, confiando apenas na Providência Divina, que tarda, mas não falta" (ANHAIA MELLO, 1954, p.2). E, finalmente, havia a situação das cidades, que:

[M]aiores ou menores - polis, metropolis ou megalopolis, [estavam] crescendo sem plano, congelando nos centros, e se enquistando de "ghettos" e favelas nas periferias, e sem equipamento social adequado e serviços públicos ou de utilidade pública a altura das necessidades; teatro de uma exploração imobiliária criminosa e desumana. (ANHAIA MELLO, 1954, p. 2 - grifos no original).

Para concluir essa parte de sua apresentação, Anhaia Mello fecha o trecho da seguinte maneira: "O quadro é negro, mas real” (ANHAIA MELLO, 1954, p. 2).

\footnotetext{
${ }^{8}$ Sobre a participação de Anhaia Mello como conselheiro informal de Fábio Prado, ver Paulo Duarte (1976). Sobre as políticas urbanísticas de Fábio Prado, consultar Silva 2004; Campos 2002. Sobre a prefeitura de Prestes Maia, ver Carpintéro (1998); Campos (2002); Toledo (1996). Finalmente, sobre o plano de urbanização elaborado durante a administração de Lineu Prestes, consultar Leme (2011); Siwi (s/d).
} 
Nessa sequência, é evidente o esforço narrativo para criar no público um sentimento de preocupação e a consciência da necessidade urgente de transformações no país. Para tanto, a estratégia de Anhaia Mello é construir um cenário trágico e marcado, no fundamental, por uma oposição subjacente entre civilização e barbárie, sendo esta segunda o signo dominante no Brasil. Há o abandono de imensas regiões; há a figura do homem do campo, perdido e sem condições de ser incorporado à cultura (ou seja, à civilização); há os povoados esquecidos pelo Estado e marcados pela poeira e pela lama; e há, enfim, as cidades tomadas por interesses mesquinhos e individualistas. Seria urgente, portanto, inverter a situação: que aquelas imensas áreas fossem ocupadas de maneira racional; que o homem do campo fosse integrado à cultura; que o Estado portador por excelência da ordem e, portanto, da civilização - desse conta dos povoados e vilas esquecidos e que as cidades fossem reordenadas para que valores coletivistas substituíssem os então em voga em seus territórios (coletivismo que, por sinal, também aparece nas suas falas de início de carreira, como pode ser verificado acima). Para complementar sua estratégia de convencimento, esse quadro é apresentado como uma simples constatação, e não resultado de uma opinião interessada: "Como disse, são fatos. As opiniões são livres, mas os fatos são sagrados” (ANHAIA MELLO, 1954, p. 2).

Construído o cenário dramático e transformado o drama em fato constatado, Anhaia Mello passa imediatamente à explicação do que era necessário fazer:

\footnotetext{
É preciso considerar o problema urbanístico regional, que não se resolve com avenidas, viadutos e pracinhas ajardinadas. / Si urbanismo é arte de correlação e integração - problema de função, de textura, de economia e síntese estética - só pode ser realmente praticado no plano regional, e na maior das regiões - $\underline{\text { a Nação. }}$. (ANHAIA MELLO, 1954, p. 2 - grifos no original).
}

A solução, portanto, seria encarar os problemas urbanos transcendendo os limites tradicionais da cidade. Seria preciso pensar políticas urbanas em nível nacional, levando em conta diversos conglomerados de cidades - que deveriam ser articuladas de maneira harmoniosa entre si -, e garantindo, assim, mecanismos que evitassem o futuro desolador que se avizinhava. No entanto, reformar cada uma das cidades de todo o Brasil não soava uma solução condizente com a urgência desenhada no início da palestra. De fato, havia uma hierarquia a ser seguida: "Os destinos da maior cidade do Brasil interessam à Nação Brasileira e ao Estado de São Paulo. Itú ou Santa Cruz do Rio Pardo poderão resolver de maneira domestica os seus problemas urbanísticos; São 
Paulo, não" (ANHAIA MELLO, 1954, p. 13). Ou seja, era São Paulo e talvez o Rio de Janeiro, que precisava $(\mathrm{m})$ receber a atenção nacional.

Os primeiros passos para se promover um urbanismo regional eram de ordem legislativa e institucional. Anhaia Mello sugere a criação, em municípios como São Paulo, de uma super-secretaria, que ele denomina "Bureau de Planejamento", congregando tanto atividades de pesquisa e planejamento - que seria o departamento de Urbanismo -, quanto a execução das obras - a Secretaria de Viação e Obras Públicas. Uma especificidade da proposta de Anhaia Mello era dar certa autonomia aos urbanistas, frente às rotinas burocráticas do Estado: "O planejamento nas suas atividades de pesquisa, de investigação, de previsão, de inquérito e de interpretação de dados, tem que estar fóra e acima da rotina administrativa, para poder agir e produzir" (ANHAIA MELLO, 1954, p. 4).

Esse Bureau responderia diretamente ao prefeito e estaria ligado à Comissão de Orientação do Plano do Município. Ao mesmo tempo, seria necessária a criação de órgãos similares nos níveis estadual e nacional. São Paulo e demais estados precisariam elaborar seus respectivos Planos Regionais de Urbanização, e o Brasil deveria ter um Plano Nacional - incluindo nesse esquema um Conselho Nacional de Urbanismo, com seus respectivos desdobramentos estaduais e municipais. Finalmente, esse grande aparato institucional deveria ser amparado por uma legislação específica, que ordenaria a concentração populacional, o uso da terra, a distribuição das indústrias, entre outras coisas - tudo a partir dos princípios da descentralização e do controle do crescimento dos núcleos urbanos.

O trabalho que essa estrutura administrativa deveria desempenhar seria polêmico, pois, partia de uma tese que, embora correta da perspectiva de Anhaia Mello (1954), estava longe de ser compartilhada pela maioria: “A tese da limitação do crescimento é incontestável. Desagrada a muita gente, porque põe termo a muita exploração imobiliária, a muita fortuna facil - mas sociedade é uma organi[z]ação sob uma autoridade". Além disso, o urbanista complementa: "O desequilíbrio do molde populacional já [é] tremendo, se agrava todos os anos. As previsões para o ano de 2.050 são da ordem de 16.000.000 de habitantes para o Estado todo, mais $\underline{8.000 .000 \text { na }}$ Capital!!!" (ANHAIA MELLO, 1954, p. 14 - grifos no original).

Esses dois trechos, de fato, articulam as duas representações do futuro de São Paulo em jogo em sua palestra. Ou São Paulo se tornaria um bom lugar para viver - o que somente seria possível se a limitação do crescimento da cidade fosse implementado 
- ou a metrópole estaria condenada ao caos, com mais de oito milhões de habitantes no ano de 2050.

É importante considerar, nesse contexto, que a representação hegemônica do futuro de São Paulo também previa a continuidade do seu aumento populacional. A diferença, em relação a Anhaia Mello, era que esse crescimento era visto como algo positivo - maior era sinônimo de melhor. A proposta e, de fato, a força do discurso de Anhaia Mello estavam em inverter o valor tradicional que se dava à expansão ilimitada da cidade, associando maior a pior, através das acusações de que o crescimento urbano só era interessante para uma especulação imobiliária criminosa.

Na segunda metade da década de 1950, o discurso hegemônico sobre São Paulo deixa de ser otimista em relação ao seu crescimento contínuo e passa a pôr em primeiro plano, os problemas, não mais os benefícios, que uma grande metrópole oferecia aos seus habitantes. Isso é especialmente evidente ao se acompanhar as falas de geógrafos e sociólogos que, a partir de então, passaram a ser presença constante nos debates sobre São Paulo, conforme, por exemplo, Azevedo (1958); Fernandes (2008).

Não é o objetivo deste artigo recuperar de modo detalhado as representações que se consolidaram depois da atuação de Anhaia Mello nos debates e nas representações da cidade. Esse trabalho exigiria muito mais espaço do que o disponível aqui. De qualquer forma, vale mencionar, novamente, Florestan Fernandes que, em texto de 1954, produzido no contexto das comemorações dos 400 anos de São Paulo, dizia:

\begin{abstract}
Tendo-se em vista as condições em que se processaram a desagregação da antiga ordem social escravocrata e senhorial e a formação incipiente da nova ordem de classes sociais, a urbanização representa e assegura a evolução para situações sociais de vida historicamente desejáveis no Brasil. Baste-nos um exemplo: com ela é que se inicia o aparecimento de condições sociais que comportam o livre exercício do voto, a organização de partidos de massas, a ascensão política das classes médias e das camadas populares, o advento de correntes e instituições políticas compatíveis com a instauração de um regime democrático. (FERNANDES, 2008, p. 191)
\end{abstract}

Em contraste, cinco anos depois, em 1959, o mesmo sociólogo, olhava para a cidade de São Paulo a partir de uma perspectiva bastante mais pessimista:

Os espaços ocupados o foram nas condições mais precárias. Com frequência, sem serviços regulares de abastecimento de água potável, de esgotos, de assistência médica, de ensino, de calçamento, de iluminação pública etc. Nas áreas onde se processou o crescimento vertical propriamente dito, nada se fez para reajustar as vias de comunicação, os serviços de águas ou de esgotos, de calefação etc., às estruturas dos prédios grandes e à maior concentração demográfica. No conjunto, o homem conquistou o espaço, mas não o domesticou no sentido urbano. A jornada para o trabalho ou deste para o lar, 
por exemplo, está cheia de aventuras, de inconvenientes e de provações, produzindo um encurtamento indireto do período útil da vida humana. Deste ângulo, as perspectivas são sombrias, pois a menor calamidade pública exporia a cidade e seus habitantes a crises terríveis, dadas as lacunas do abastecimento de água e de víveres, das formas de proteção da saúde e dos meios de preservação da ordem. (FERNANDES, 2008, p. 270-271).

Anhaia Mello é um dos principais responsáveis por essa mudança de humores, embora o discurso que se tornou hegemônico desse momento em diante - e no qual falas como a de Florestan Fernandes têm um lugar de destaque - também fizesse críticas à cidade reduzida que o urbanista propunha como alternativa para escapar do caos. Ou seja, o discurso hegemônico foi substituído por outro, sem que nenhum deles coincidisse com a perspectiva de Anhaia Mello.

Na palestra em exame, Anhaia Mello lança mão de algumas referências teóricas para sustentar sua imagem de cidade. Entre elas, merecem destaque as menções a Carta de Atenas, bem como as quatro funções da cidade proposta pelo documento "Residência, Trabalho, Recreio e Circulação" (ANHAIA MELLO, 1954, p. 23), sem contar a farta bibliografia internacional. Entre os autores citados pelo urbanista, Ebenezer Howard, Patrick Geddes e os fundadores da Regional Planning Association of America, Lewis Mumford, Clarence Stein e Henry Wright merecem um lugar especial sobretudo, e respectivamente, por conta dos conceitos de cidade-jardim, de planejamento regional e de federação de cidades. ${ }^{9}$ Além disso, esses autores inspiram outras facetas de Anhaia Mello. Inclusive, é de Geddes que o urbanista retira sua filosofia da história: "Patrick Geddes esboçou os seis estágios do desenvolvimento urbano, dos quais três na curva ascendente e três na descendente. São êles: eopolis, polis, metrópolis [curva ascendente]; megalopolis, tiranopolis, necropolis [curva descendente]" (ANHAIA MELLO, 1954, p. 33). A primeira forma de cidade, a “eopolis", era aquela que oferecia uma espécie de "espírito comunitário", que Anhaia Mello acreditava ser "a raiz essencial da vida urbana":

Eopolis: É a comunidade aldean, e o aldeão é o homem eterno. Desenvolvimento da habitação permanente e dos orgãos externos de associação. É a mais duradoura das fórmas coletivas, resistindo a todas as transformações da civilização. É o prototipo da cidade. Os outros tipos deferenciados urbanos florescem e desaparecem; mas a eopolis persiste; é a raiz essêncial da vida urbana. (ANHAIA MELLO, 1954, p. 33).

\footnotetext{
${ }^{9}$ Sobre esses autores, é interessante consultar o trabalho de Peter Hall (2011), que os reúne em torno de um grande projeto urbanístico e social, centrado nas cidades-jardim. Sobre os usos que Anhaia Mello fazia dessas referências, ver Feldman (2005).
} 
O estágio seguinte seria a "polis", cuja descrição era baseada nas antigas cidades-estado gregas e nas tardo-medievais cidades-estado italianas. Esse era o modelo de cidade que Anhaia Mello usava para propor um futuro alternativo para São Paulo, pois eram núcleos populacionais relativamente pequenos e organizados regionalmente:

Polis: Associação de aldeias para a defesa comum. Começo de mecanização e de divisão do trabalho. Melhores oportunidades para educação e cultura do corpo e do espírito. Vida diferenciada porém homogenea. Unidade cívica e vizão comum da vida, simbolizada na Catedral e a Casa Municipal. Cultura moral e estética. Equilíbrio regional. (ANHAIA MELLO, 1954, p. 33).

São Paulo estaria no terceiro estágio, o último da curva ascendente e, portanto, prestes a iniciar o processo de decadência:

\begin{abstract}
Metropolis: Dentro da região uma cidade emerge, tirando partido da locação estratégica ou de comando das vias de transporte e comunicação. Atrái habitantes e se transforma em metropole, cidade-mãe. Especialização. A mecanofatura suplanta a agricultura e o artezanato. Luta entre os donos das máquinas e seus operadores. Cortiços; congestionamento e congelamento. $\mathrm{O}$ mecânico em oposição ao orgânico e ao biológico. (ANHAIA MELLO, 1954, p. 33).
\end{abstract}

Embora a "metropolis" fosse ainda parte da curva ascendente no desenvolvimento das cidades, suas características, tal como apresentadas por Anhaia Mello, eram sobretudo negativas. Entretanto, antes de analisar essas características, é interessante destacar uma relação implícita entre esse modelo geral de metrópolis e uma imagem comum de São Paulo no momento, já então representada como uma cidade cujo desenvolvimento se deu, em grande parte, graças à sua posição geográfica, uma espécie de entroncamento natural de diversos caminhos. Como observou Caio Prado Jr. nessa mesma época:

Essas três grandes passagens - para nordeste, pelo vale do Paraíba; para o norte, por Campinas e Mogi Mirim, em direção a Minas e Goiás; para oeste e sul, por Sorocaba e Itapetininga, em direção às capitanias meridionais da colônia - essas três grandes passagens determinadas pelo relevo do solo seriam os principais fatores que condicionariam a expansão colonizadora do planalto paulista. É que elas representam as únicas possíveis, tanto para o norte como para oeste e sul. Ladeando-as, na região norte, levanta-se a Mantiqueira, barreira contínua de cumes que ultrapassam 2 mil metros. Ao sul, é a serra de Paranapiacaba, que com sua topografia acidentada e difícil impede as passagens e o estabelecimento do homem. Este é assim impelido para as depressões que acompanham aqueles terrenos acidentados. É nelas por isso que se estabelece o povoamento, é nelas que se desenvolve a colonização. E todas as três convergem para São Paulo, que se constitui assim como nó deste sistema topográfico. (PRADO JR, 2012, p. 113). 
Essa condição foi reatualizada no final do século XIX, pelas estradas de ferro, que se sobrepunham a esses caminhos naturais, além de conectar a cidade ao porto de Santos. Em meados do século XX, eram as estradas de rodagem que reforçavam São Paulo como uma "Roma" dos trópicos - afinal, como diz o ditado, "todos os caminho levam a Roma". ${ }^{10}$

No caso da palestra em questão, o esforço de Anhaia Mello era o de associar essa condição de "nó de um sistema topográfico", então entendida como privilegiada, a uma espécie de "desonestidade", onde uma cidade central se beneficiaria indevidamente dos recursos de suas cidades vizinhas. Além disso, também a indústria concentrada, motivo frequente de orgulho para os paulistanos, era apresentada em cores desfavoráveis, afinal, ela eliminava atividades tradicionais como a agricultura e o artesanato, e acirrava a luta de classes. A "metropolis", finalmente, apresentava uma série de problemas específicos - cortiços, congestionamento, congelamento - que, cada vez mais frequentemente, eram centrais nos debates urbanísticos do momento. A crítica ao modelo concorrente de urbanismo era fortemente focada na explicitação desse tipo de problemas que, na prática, seus defensores não conseguiam resolver. Portanto, chamar a atenção para isso na caracterização genérica da "metropolis" era mais um ataque de Anhaia Mello aos seus adversários - intelectuais e, ao mesmo tempo, políticos, pois essas categorias se misturavam na São Paulo dos anos 1950.

Os próximos estágios, o futuro, portanto, são apresentados de maneira especialmente interessante. Anhaia Mello, ainda com a ajuda de Geddes, seleciona um conjunto de características que, de fato, podiam já ser identificadas na São Paulo de então. Uma forma tanto de demonstrar a verossimilhança da filosofia da história apresentada, quanto de reforçar o sentimento de urgência para evitar o pior:

Megalopolis: O crescimento continúa em virtude da velocidade adquirida. Início do declinio sob o ponto de vista humano e social. Grandeza e fôrça. Triunfo do mecanismo e deshumanização. A vida humana subordinada à riqueza e à exploração generalizada. Anonimato. Burocracia, Indiferença cívica, passividade e resignação. Educação quantitativa. Exploração das massas, conflitos e tensão permanentes.

Tiranopolis: E o crescimento continua... Gangesterismo e cezarismo. Desaparece a consciência civica. A ordem só pode ser mantida pela violencia e ditadura. Censura generalizada da opinião. Êxodo. (ANHAIA MELLO, 1954 , p. 34).

Vale a pena notar que a insistência do autor na tecla do crescimento tinha uma relação especial e bastante irônica, com a representação típica de São Paulo naquele

\footnotetext{
${ }^{10}$ Sobre os desenvolvimentos rodoviários de São Paulo, ver Porta (2004).
} 
momento. Parte das celebrações do IV Centenário, sobretudo a publicitária, dizia ser São Paulo a cidade que mais rápido crescia no mundo. ${ }^{11}$ Obviamente, Anhaia Mello não via nisso nenhum motivo para comemorar. Por isso, repetir que o crescimento era o que conduzia uma "metrópolis" aos estágios de decadência era também uma forma de provocar essa representação hegemônica e propor sua ressignificação. São Paulo já seria, com certeza, uma "metropolis". Sua condição de crescimento talvez a tivesse transformando rapidamente em uma "megalopolis". E dada a velocidade adquirida, o estágio de "tiranopolis" não estaria distante.

Enfim, dentre as representações de futuro apresentadas por Anhaia Mello, eram, sobretudo, os estágios de "metropolis" e "megalopolis" aqueles que interferiam diretamente no discurso hegemônico sobre São Paulo. Vários elementos do ponto de vista desafiante, encarnado por ele, coincidiam com a representação dominante até então: o crescimento, a velocidade, a indústria, a concentração, e mesmo o anonimato, a burocratização, a mecanização. Contudo, como já se chamou a atenção, os valores desses elementos estavam invertidos em cada uma das perspectivas. E é justamente a partir do que há de comum entre elas que o tipo de discurso apresentado por Anhaia Mello modifica a representação hegemônica. O futuro continuaria mais ou menos o mesmo: São Paulo seguiria crescendo - essa expectativa era, de fato, uma constante nas representações do futuro de São Paulo desde o final do século XIX. Contudo, na década de 1950, invertem-se os valores desse crescimento. Antes, o que era bom, passa a ser visto como algo ruim. Essa inversão, em parte provocada por Anhaia Mello, vai se consolidar como hegemônica graças a uma transformação no, digamos, regime de produção de representações da cidade, em que os urbanistas e o urbanismo foram substituídos por sociólogos, geógrafos dentre outros intelectuais da humanidade.

Nesse sentido, a cidade e seu futuro deixaram de ser hegemonicamente pensadas a partir dos critérios do urbanismo, enquanto passaram a primeiro plano as representações da cidade através de critérios sociais. O crescimento da universidade, as transformações urbanas em São Paulo, o enfraquecimento dos discursos tradicionais sobre a metrópole e a "ocupação" do debate público sobre São Paulo por parte desses novos intelectuais são os principais elementos na transformação da formulação da representação hegemônica da metrópole. Mas, isso também foge aos objetivos deste artigo. Portanto, voltemos à palestra de Anhaia Mello:

\footnotetext{
${ }^{11}$ Como por exemplo os jornais O Estado de São Paulo e Folha da Noite de 25 janeiro de 1954, dia do aniversário de 400 anos de São Paulo.
} 
Finalmente, o último estágio apontado pelo autor, era a morte da cidade: "Necropolis: O fim do ciclo. A vida social desaparece e da cidade resta apenas o arcabouço. Doenças, fome, guerra civil. Assim aconteceu em Babilônia, Nínive, na Roma das invasões" (ANHAIA MELLO, 1954, p. 34). Desse estágio, São Paulo ainda estava distante, mas era preciso trabalhar para que a cidade nunca se aproximasse dele:

\begin{abstract}
É preciso, pois impedir, por todos os meios, que o processo de acumulação de pessôas e atividades, pseudo urbano, se desenvolva na fase decadente, combatendo em tempo a economia metropolitana. É preciso lutar contra a apoplexia dessa falsa prosperidade. Lutar contra o aumento de população, além dos limites razoáveis; lutar contra os meios mecânicos que favorecem o congestionamento; lutar contra a extensão indefinida da área urbana; lutar contra tudo que é apenas maior em vez de ser melhor. / É preciso, em resumo, saber utilizar socialmente os bens da nossa época, reorientando o desenvolvimento urbano; pondo o mecânico à serviço do orgânico; derrubando a máquina e a ciência do pedestal reservado ao homem. / As cidades crescem, mas o homem é sempre o mesmo. No desenvolvimento para supercidades o ambiente não gera super-homens mas sub-homens. A supercidade, socialmente, é uma subcidade. Aliás, os super-homens são notáveis justamente pela sua sensibilidade, pela sua cultura, por serem mais intensamente humanos; marginais no ambiente megalopolitano. (ANHAIA MELLO, 1954, p. 34).
\end{abstract}

Fica claro nesse trecho, o voluntarismo indicado no início de sua fala - bastaria força de vontade, amparada nos "bens de nossa época", para reverter o destino "natural" das grandes cidades. Aparece também uma concepção de ser-humano, possuidor de uma natureza ahistórica, ainda que seu potencial de realização estivesse sujeito às condições sociais. Esse "homem" apenas se realizaria plenamente fora da grande cidade, enquanto a mesma grande cidade seria um inibidor daquela realização. Além disso, Anhaia Mello faz um apelo ao retorno do antropocentrismo. Em algum momento depois da Revolução Industrial, as máquinas teriam passado ao primeiro plano de interesses, subordinando a humanidade aos interesses mecânicos. Para que o "homem" se tornasse novamente o centro das atenções era preciso, enfim, que o ambiente fosse propício - ou seja, era preciso construir novas e adequadas cidades, era preciso acabar com as metrópoles.

Até esse momento da palestra, Anhaia Mello vinha fazendo críticas mais abrangentes ao modelo de urbanismo que apostava no crescimento indefinido da cidade. A partir daí, a crítica passa a ser focada mais especificamente no modelo de cidade adotado na urbanização de São Paulo. Conforme o urbanista, a principal característica estrutural da metrópole paulista era sua configuração a partir de um molde de círculos concêntricos - como ondulações provocadas por uma pedra ao bater na água ou como a figura tradicional de um alvo. Esse molde favoreceria que a cidade fosse: "crescendo 
indefinidamente, patològicamente, com prejuízo da própria finalidade e da razão de sua própria existência" (ANHAIA MELLO, 1954, p. 35). Adiante, o urbanista continua:

\begin{abstract}
Êste é o molde espacial do metropolitanismo, pois: zonas de transição no centro e na periféria; zonas de transição que se transformam, fatalmente, uniformemente, em áreas de deterioração, e eis o cortiço em cena. O cortiço, e seu cortejo de males. O cortiço, produto de processos ecológicos e sociais, é criação típica do metropolitanismo (ANHAIA MELLO, 1954, p. 35 - grifos no original).
\end{abstract}

$\mathrm{Na}$ descrição de sua filosofia da história das cidades, o cortiço - espécie de síntese dos males metropolitanos para Anhaia Mello - já aparecia como um elemento problemático, típico das megalópoles. Aqui, ele volta à cena não só como resultado inevitável de um tipo de desenvolvimento urbano, mas também como fruto irresponsável de uma proposta de urbanismo. A crítica atingia tanto as teorias urbanísticas que defendiam esse modelo de cidade, organizada em círculos concêntricos, quanto especificamente às reformas urbanas promovidas na década anterior em São Paulo. Há, aqui, uma citação implícita ao "Plano de Avenidas", elaborado por Prestes Maia, no final dos anos 1920, aplicado a São Paulo durante o Estado Novo com a pretensão de favorecer a transformação da cidade em uma "cidadealvo" (PRESTES MAIA, 1930). Apesar de implícita, a referência era bastante clara para seu público, pois o "Plano de Avenidas" era por demais famoso naquele momento, sobretudo, entre os urbanistas locais.

Esse "Plano de Avenidas", reconhecido como uma referência fundamental do urbanismo brasileiro e, também, exemplo bem acabado do modelo progressista de urbanismo, ${ }^{12}$ era, enfim, acusado de ser produtor de cortiços. Um golpe de Anhaia Mello, sem misericórdia, na principal realização de seus adversários. O urbanista não faz nenhuma concessão: é um tipo de projeto que deve ser abandonado por completo. A esperança de futuro para São Paulo estaria justamente na substituição deste modelo: “A limitação deve ser forçada, pôr fatos exteriores de planejamento orgânico e criador. $\mathrm{O}$ ciclo de crescimento é reversível, por meio de regionalismo e polinucleação" (ANHAIA MELLO, 1954, p. 35). E acrescenta: “As atuais cidade, tipo 'cible', ou alvo, mononucleadas, devem ser substituídas por cidades tipo cacho, 'grappe', polinucleadas, reunidas em federação" (ANHAIA MELLO, 1954, p. 47).

\footnotetext{
${ }^{12}$ Sobre o "Plano de Avenidas", ver Carpintéro (1998); Campos (2002); e Toledo (1996).
} 
Essa federação de cidades em formato de "cacho" seria o planejamento conforme um conjunto de princípios caros aos autores que Françoise Choay (2010) agrupa em torno do modelo culturalista de urbanismo, e que Peter Hall (2011) reúne no grande projeto das cidades-jardim:

Três são os conceitos básicos, criadores dessa ação: 1/ A cidade jardim; 2/ A idea de Radburn; 3/ A "neighborhood unit"; ou, em outras palavras: 1/ a cinta verde para a limitação da extensão da cidade, e abastecimento de "fresh food"; 2/ a superquadra, que permite a convivência pacifica com o automóvel; e 3/ a unidade de vizinhança, que permite a rearticulação social e comunitária nas urbes (ANHAIA MELLO, 1954, p. 38).

Em contraste com o urbanismo dominante em São Paulo, a cidade do futuro apresentada por Anhaia Mello promoveria uma transformação radical da sociedade, e não só um conjunto restrito de intervenções urbanísticas. As relações humanas também estavam em jogo. A cidade, nesse sentido, tinha um papel determinante, no sentido forte do termo, na definição de como as pessoas se relacionariam entre si:

As relações primárias [de família, de vizinhança, de comunidade] foram substituídas pelas secundárias [superficiais, burocráticas, transitórias, rápidas], o que exerce uma influência desintegradora na ordem material e moral, responsável pelo aumento de vicios e crimes nas metropoles (ANHAIA MELLO, 1954, p. 45).

Por outro lado, nas cidades-jardim: "Os contatos são fáceis e a amizade é cultivada. A atitude de um pedestre para com outro, é sempre cordial e amiga; muito diversa da do motorista apressado e... malcriado" (ANHAIA MELLO, 1954, p. 46). São duas certezas inquestionáveis, dois princípios: em primeiro lugar, o efeito disruptivo e anti-social das grandes aglomerações urbanas; e, em segundo lugar, o efeito harmonizador das pequenas comunidades. O discurso de Anhaia Mello não deixa espaço para relativizações. Não seria possível haver harmonia em uma grande cidade; não faria sentido haver caos em uma pequena comunidade. Essas alternativas cruzadas, que talvez fossem objeto de debate em outro contexto, não têm lugar na fala desse urbanista . É importante destacar que, no limite, esses princípios são arbitrários, não há sustentação empírica para eles - embora houvesse estudos, alguns produzidos por sociólogos como Tönnies (referência para Florestan Fernandes) ou Robert Woods (referência para Anhaia Mello) que ajudassem a argumentar em um sentido ou no outro. De qualquer forma, a principal característica da estratégia de convencimento adotada 
por Anhaia Mello era repetir esses princípios, cada vez com uma figura narrativa diferente, como nos exemplos anteriores.

Essa comunidade ideal era vista pelos urbanistas que representavam o modelo hegemônico como utópica e irrealizável. Um exemplo disso é o um trecho do Programa de Melhoramentos Públicos para a cidade de São Paulo, plano urbanístico encomendado pela prefeitura de São Paulo, sob administração de Lineu Prestes (1950-51), ao renomado "urbanista" estadunidense Robert Moses (1950). Este autor, assim como Prestes Maia, era um entusiasta do urbanismo "pragmático" e condenava justamente a impraticabilidade das propostas "revolucionárias":

\begin{abstract}
Sao Paulo has already decided the main outlines and features of its City plan. It would be futile to quarrel with this decision, even if we were disposed to do so, which is not the case. To use the conventional physiological metaphor, the skeletal system is determined; the heart or busines center is fixed as are most main arteries; the lungs are the interior suburbs, usually found outside the city limits. Any city plan based upon radical theories of decentralization and dispersion of population, outlying satellite towns, green belts devoted to parks, landscaping, truck farms and what not, separating one neighborhood from another and bans on high buildings an on all concentrations of population, is apparently no part of Sao Paulo psychology, trend and ambition, and any plan, zoning resolution and program of improvements must, if they are to be realizable, proceed on the assumption that the average Paulista, however proud of his City, eager for its advancement and jealous of its reputation, is a middle-of-the-road citizen, at heart no revolutionary in his philosophy of municipal administration. (MOSES, 1950, p. 11-12).
\end{abstract}

Nesse trecho, é possível identificar a estratégia retórica de Moses para desqualificar o tipo de ponto de vista que Anhaia Mello representava. Em primeiro lugar, ele reconhece uma série de alternativas para os problemas urbanos que não fazem parte de seu repertório. Contudo, classifica essas alternativas como "teorias radicais" e dispensa todas em um só movimento. Ele não explica porque a descentralização, os cinturões-verdes ou quaisquer outras soluções "revolucionárias" não seriam boas saídas para os problemas urbanos. Simplesmente, Moses constata que tais soluções não condizem com o tipo de cidade que é São Paulo. A metrópole já teria uma "natureza" e os urbanistas deveriam lidar com ela tal como estava dada. Tentar mudar essa "natureza" seria uma escolha ruim, sobretudo porque demandaria uma quantidade enorme de trabalho e energia, que poderiam e deveriam ser usados em outra direção. Portanto, a oposição não era entre um plano melhor ou pior para a cidade, mas sim entre dois conjuntos de soluções mais ou menos factíveis.

Essa diferença diz respeito também às posições que, pelo menos em São Paulo, para usar novamente os termos de Choay, os urbanistas progressistas e os urbanistas 
culturalistas tenderam a ocupar no Estado ao longo do tempo. Os culturalistas (ou "revolucionários") tiveram poucas oportunidades de aplicar suas teorias a grandes cidades. Mesmo quando estiveram em posições executivas, não conseguiram efetivamente implantar suas "teorias radicais". Anhaia Mello, por exemplo, tanto foi prefeito de São Paulo, por um curto período, quanto secretário de Viação e Obras Públicas do estado de São Paulo, neste caso, por longo período no cargo, com condições de testar suas teorias sobre urbanização regional. Ao passo que os progressistas (ou "pragmáticos") puderam, sim, experimentar seus planos urbanísticos, como o caso exemplar de Prestes Maia.

Nesse sentido, o cenário que se desenhou aos poucos foi: de um lado, um urbanismo aplicado que prometia uma cidade desembaraçada e funcional, mas não dava conta de cumprir com suas promessas; e, de outro, um urbanismo teórico que prometia um paraíso na terra, mas não encontrava chances reais de ser posto à prova.

Em suma, o futuro de São Paulo apresentado por Anhaia Mello ajudava na ressignificação do discurso hegemônico sobre o futuro da metrópole - ou, enfim, ajudava a transformar a produção do futuro da cidade. Depois de 1954, a crítica que Anhaia Mello faz ao otimismo em relação ao crescimento indefinido de São Paulo rapidamente contaminou a maior parte das representações da cidade. Por outro lado, o futuro alternativo - e também otimista - que vinha colado à crítica não teve o mesmo sucesso. Se Anhaia Mello atingiu, em cheio, o tipo de urbanismo representado por seus adversários, o contra-ataque não deixou por menos, e Anhaia Mello não conseguiu escapar da acusação de propor uma alternativa utópica e irrealizável. 


\section{REFERÊNCIAS}

ABREU, Alzira Alves de (Org.). Dicionário Histórico-Biográfico Brasileiro - Pós1930. Rio de Janeiro: Ed. FGV, 2001.

ANHAIA MELLO, Luiz de. Urbanismo. Boletim do Instituto de Engenharia, São Paulo, n. 42, nov. de 1928.

ANHAIA MELLO, Luiz de. O problema da habitação. Digesto Econômico, São Paulo, vol. XVI, n. 72, nov. de 1950.

ANHAiA MELlO, Luiz de. O Plano Regional de São Paulo. Uma Contribuição da Universidade para o estudo do "Um Codigo de Ocupação Licita do Solo". Monografia/Palestra. FAU; USP: São Paulo, 1954.

ARRUDA, Maria Arminda do Nascimento. Metrópole e cultura: São Paulo no meio do século XX. Bauru: Edusc, 2001.

AZEVEDO, Aroldo (Org.). A cidade de São Paulo: Estudos de geografia urbana. vol. 1-4. Cia. Editora Nacional: São Paulo, 1958.

BALLON, Hilary; JACKSON, Kenneth (Ed.). Robert Moses and the modern city: The transformation of New York. New York, London: W. W. Norton \& Company, 2007.

BRESCIANI, Maria Stella. Estudo da trajetória profissional do engenheiro-arquiteto Luiz I. R. de Anhaia Mello. In: SALGADO, Ivone; BERTONI, Angelo (Org.). Da construção do território ao planejamento das cidades: competências técnicas e saberes profissionais na Europa e nas Américas (1850-1930). São Carlos: RiMa, 2010.

BRESCIANI, Maria Stella. As múltiplas linguagens do urbanismo em Luiz de Anhaia Mello: técnica, estética e política. In: FARIA, Rodrigo; CERASOLI, Josianne; LIRA, Flaviana (Org.). Urbanistas e urbanismo no Brasil: Entre trajetórias e biografias. São Paulo: Alameda, 2014.

CAMPOS, Candido Malta. Os rumos da cidade: Urbanismo e modernização em São Paulo. São Paulo: Senac, 2002.

CARO, Robert A. The power broker: Robert Moses and the fall of New York. New York: Vintage Books, 1975.

CARPINTÉRO, Mariza Varanda Teixeira. Em busca da imagem: a cidade e seu figurino (São Paulo 1935-1954). 1998. Tese (Doutorado em História) - Universidade Estadual de Campinas, Instituto de Filosofia e Ciências Humanas, Programa de Pósgraduação em História, Campinas, 1998.

CERTEAU, Michel de. A escrita da história. Rio de Janeiro: Forense Universitária, 1982.

CHOAY, Françoise. O urbanismo. São Paulo: Perspectiva, 2010. 
DUARTE, Paulo. Memórias: Selva oscura. vol. III. São Paulo: Hucitec, 1976.

FELDMAN, Sarah. Planejamento e zoneamento. São Paulo: 1947-1972. São Paulo: Edusp/Fapesp, 2005.

FERNANDES, Florestan. Mudanças sociais no Brasil. São Paulo: Global, 2008.

FICHER, Sylvia. Os arquitetos da Poli: Ensino e profissão em São Paulo. São Paulo: Fapesp; Edusp, 2005.

GARCIA, Sylvia G. Destino ímpar: sobre a formação de Florestan Fernandes. São Paulo: Editora 34, 2002.

HALL, Peter. Cidades do amanhã: uma história intelectual do planejamento e do projeto urbanos no século XX. São Paulo: Perspectiva, 2011.

LEME, Maria Cristina. Urbanismo: a formação de um conhecimento e de uma atuação profissional. In: BRESCIANI, Maria Stella (Org.). Palavras da cidade. Porto Alegre: Ed. da UFRGS, 2001.

LEME, Maria Cristina. A presença norte-americana e a transformação de São Paulo no pós-guerra. In: LANNA, Ana Lúcia; PEIXOTO, Fernanda; LIRA, José Tavares; SAMPAIO, Maria Ruth (Org.). São Paulo, os estrangeiros e a construção das cidades. São Paulo: Alameda, 2011.

MEYER, Regina Maria Prosperi. Metrópole e urbanismo: São Paulo anos 50. Tese (Doutorado em Arquitetura) - Universidade de São Paulo, Faculdade de Arquitetura e Urbanismo, Programa de Pós-graduação em Arquitetura, São Paulo, 1991.

MICELI, Sergio (Org.). História das Ciências Sociais no Brasil. vol. II. São Paulo: Ed. Sumaré; Fapesp, 1995.

MICELI, Sergio (Org.). História das Ciências Sociais no Brasil. vol. I. São Paulo: Ed. Sumaré, 2001a.

MICELI, Sergio. Intelectuais à brasileira. São Paulo: Cia. das Letras, 2001 b.

MICELI, Sergio. Vanguardas em retrocesso: ensaios de história social e intelectual do modernismo latino-americano. São Paulo: Cia das Letras, 2012.

MOSES, Robert. Programa de Melhoramentos Públicos para a cidade de São Paulo. Nova York: International Basic Economic Corporation; IBEC Technical Services Corporation, 1950.

PONTES, Heloísa. Destinos mistos: os críticos do Grupo Clima em São Paulo (194068). São Paulo: Cia. das Letras, 1998.

PORTA, Paula (Org.). História da cidade de São Paulo. vol. 3: a cidade na primeira metade do século XX. São Paulo: Paz e Terra, 2004. 
PRADO JR., Caio. O fato geográfico na formação e no desenvolvimento da cidade de São Paulo. In: PRADO JR., Caio. Evolução política do Brasil e outros estudos. São Paulo: Cia. das Letras, 2012.

PRESTES MAIA, Francisco. Estudo de um plano de avenidas para a cidade de São Paulo. São Paulo: Companhia Melhoramentos de São Paulo, 1930.

PRESTES MAIA, Francisco. Os melhoramentos de São Paulo. São Paulo: Prefeitura Municipal de São Paulo, 1945.

SANTOS, Milton. A urbanização brasileira. São Paulo: Edusp, 2009.

SILVA, Luís Octávio da. Verticalização, expansionismo e grandes obras viárias: a modernização limitada. In: CAMPOS, Candido Malta; GAMA, Lúcia Helena; SACCHETTA, Vladimir (Org.). São Paulo, metrópole em trânsito: percursos urbanos e culturais. São Paulo: Ed. Senac São Paulo, 2004.

SIWI, Márcio. Urban Renewal North and South: The Case of São Paulo and New York During and After WWII. New York: Research Report - Rockefeller Archive Center, s/d.

TOLEDO, Benedito Lima de. Prestes Maia e as origens do urbanismo moderno em São Paulo. São Paulo: Empresa das Artes, 1996. 